\title{
Contribution of Religion/spirituality and Major Depressive Disorder to
}

\section{$\underline{\text { Altruism }}$}

Richard Neugebauer a, b, c*, Priya Wickramaratne ${ }^{\text {a, b }}$, Connie Svob ${ }^{\text {a, b }}$, Clayton H. McClintock $^{\mathrm{d}}$, Marc J. Gameroff ${ }^{\mathrm{a}, \mathrm{e}}$, Lisa Miller ${ }^{\mathrm{d}}$, Anne Conway ${ }^{\mathrm{f}}$

${ }^{a}$ Department of Psychiatry, College of Physicians and Surgeons, Columbia University, New York City, USA ${ }^{\mathrm{b}}$ Division of Epidemiology, New York State Psychiatric Institute, New York City, USA

${ }^{c}$ Department of Epidemiology, Mailman School of Public Health, Columbia University, New York City, USA

${ }^{\mathrm{d}}$ Spirituality Mind Body Institute, Department of Counseling and Clinical Psychology, Teachers College, Columbia University, New York City, USA

${ }^{\mathrm{e}}$ New York State Psychiatric Institute, New York City, USA

${ }^{\mathrm{f}}$ Anne Conway, University of Tennessee, Knoxville. 1618 Cumberland Ave, Knoxville, Tennessee. This work was accomplished while AC was at the School of Social Work, Columbia University, New York, NY

*Corresponding author.

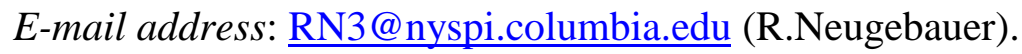

Columbia University Medical Center

New York State Psychiatric Institute

1051 Riverside Drive, Unit \#24

New York, NY 10032 


\begin{abstract}
Background. In most studies, religiosity and spirituality (R/S) are positively associated with altruism, whereas depression is negatively associated. However, the cross-sectional designs of these studies limit their epidemiological value. We examine the association of R/S and major depressive disorder (MDD) with altruism in a five year longitudinal study nested in a larger prospective study.
\end{abstract}

Methods. Depressed and non-depressed individuals and their first- and second-generation offspring were assessed over several decades. At Year30 after baseline, R/S was measured using participants' self-report; MDD, by clinical interview. At Year35, participants completed a measure of altruism. Adjusted odds ratios (AOR) were calculated using multivariate logistic regression; statistical significance, set at $\mathrm{p}<.05$. two-tailed.

Results. In the overall sample, both R/S and MDD were significantly associated with altruism, AOR 2.52 (95\% CI 1.15-5.49) and AOR 2.43 (95\% CI 1.05-5.64), respectively; in the High Risk group alone, the corresponding AORs were 4.69 (95\% CI 1.39-15.84) and 4.74 (95\% CI 1.92-11.72). Among highly R/S people in the High Risk group, the AOR for MDD with altruism was 22.55 (95\% CI 1.23-414.60) p<.04; among the remainder, it was 3.12 (95\% CI 0.63-15.30), a substantial but non-significant difference.

Limitations. Altruism is based on self-report, not observation, hence, vulnerable to bias. Conclusions. MDD's positive association with elevated altruism concurs with studies of posttraumatic growth in finding developmental growth from adversity. The conditions that foster MDD's positive association with altruism and the contribution of R/S to this process requires further study.

Keywords: Religion; Spirituality; Depression; Longitudinal; Altruism. 


\section{Introduction}

Empathy, compassion, pro-sociality and altruism (synopsized here as altruism), prized in nearly all cultures (Decety, 2010), constitute principal forms of human engagement (Eisenberg and Miller, 1987) and are essential for the survival of communal life. An established body of research has documented that clinical depression and depressive symptoms can reduce empathic capacities, inhibit social engagement, and compromise the wish and will towards altruistic and prosocial actions (Kupferberg et al., 2016). Donges and colleagues (Donges et al., 2005) find compromised empathic responses (measured with a questionnaire) among inpatients with MDD as compared with healthy controls. Much the same results are reported by Cusi and co-authors (Cusi et al., 2011) for outpatients diagnosed with MDD. Studies by Nejati et al. (Nejati et al., 2012), Clark et al. (Clark et al., 2013) and Ekinci and Ekinci (Ekinci and Ekinci, 2016) assessed empathic accuracy with Baron-Cohen's "reading the mind in the eyes" protocol (Baron-Cohen et al., 2001), or capacity for empathy using economic game paradigms or standard measures of perspective-taking and empathic concern. These investigations, nearly all of which were crosssectional in nature, found that healthy controls substantially outperformed patients with MDD on each of these markedly different tools for measuring aspects of empathy.

Some studies conducted by other groups of investigators report either that depression and empathy or altruism are unassociated, or that depression, as well as trauma, in fact increase empathic and prosocial behaviors out of the depressed individual's compassionate identification with the suffering of others (Greenberg et al., 2018, Harkness et al., 2005). Several investigators have also noted that the association between depression and altruism is sometimes bidirectional where so-called "pathological altruism" leads to depression (Zahn-Waxler and Van Hulle, 2012, Tone and Tully, 2014). However, most published work focuses on the deleterious effects of depression on altruism. Accordingly, our working hypothesis is that individuals currently 
suffering from depression or who have suffered from depression within the past several years will be less empathic and altruistic than otherwise similar individuals who have been free of depressive illness during the same period.

Early in the 1980s, our group initiated a longitudinal study to investigate risk factors for major depression among women and their offspring. The study interview generally included a clinical psychiatric diagnostic assessment focused on MDD at each time point. Beginning in the $20^{\text {th }}$ year of the study, the interview also evaluated the degree to which religiosity or spirituality (R/S) played a central role in the lives of the respondents and examined whether it influenced the likelihood of the subject experiencing episodes of MDD or of transmitting risk for depression to offspring (Fendrich et al., 1990, Weissman et al., 1997, 2016). The assessment conducted in Year35 after baseline omitted a clinical assessment of depression but added the key measure of altruism. Consequently, this study affords a scientifically strategic opportunity to examine in a longitudinal framework, the questions raised above regarding the contribution of MDD and R/S to altruism.

\section{Methods}

The first generation of subjects in the longitudinal study, Generation 1 (G1), comprised two groups of individuals: (a) depressed adults at least 18 years of age receiving pharmacological treatment for moderate to severe major depressive disorder at a Yale University outpatient clinic in New Haven Connecticut; (b) persons at least 18 years of age, free of a history of serious psychiatric disorders who had participated in a population-based psychiatric epidemiological survey conducted in the same area at around the same time (Regier and Burke, 1987).

The depressed subjects are denoted the "High Risk" group based on their meeting criteria at recruitment for a history of MDD; the second group is identified as "Low Risk" because they did 
not meet criteria for any major psychiatric disorder at recruitment. Subsequently, the biological children (Generation 2, G2) and grandchildren (Generation 3, G3) of G1 adults were invited to join their parents' group starting at age 6, irrespective of their own mental health status. G1 individuals in the High Risk group conferred elevated risk for MDD on their G2 and G3 offspring, relative to the risk of MDD in G2 and G3 offspring in the Low Risk group.(Weissman et al., 2016). Participating members of each generation in the High Risk and Low Risk Group were then interviewed at fixed intervals thereafter at baseline Time 1 (T1), then two years later, Time 2 (T2); 10 years later (T10); 20 years (T20); 25 years (T25); 30 years (T30); and 35 years (T35) (19-20). The grandchildren entered at T10. This paper focuses on the T30 and T35 assessments. At T30 G3 individuals in the current analyses ranged in age from 18 to 22; at T35, they arranged in age from 23 to 27.

This study reports (1) the sociodemographic, clinical and design features of this investigation for the overall sample and separately for the High and Low Risk groups; (2) within the High Risk and Low Risk groups, rates of altruism for each of the foregoing sociodemographic, clinical and design features followed by the association of (3) R/S (Time30) with altruism at Time35 and (4) MDD with altruism. We conclude with an exploratory analysis as to whether (5) the association of MDD with altruism is modified by R/S.

\subsection{Study Measures}

\subsubsection{Measures Administered at Year 30 Post-Baseline}

Diagnosis of Major Depression. The Schedule for Affective Disorders and Schizophrenia, Lifetime Version, (SADS-L; Mannuzza et al., 1986) — a semi-structured diagnostic interview including both lifetime and period prevalence — was administered to adults at baseline and at most subsequent study assessments. The Kiddie Schedule for Affective Disorders and 
Schizophrenia (K-SADS-E; Ambrosini, 2000) was used for children aged 6-17 years. (MDD was not assessed at T35.) Diagnoses were updated over time to satisfy criteria for DSM-III, for DSMIII-R and finally for DSM-IV (Weissman et al., 1997). The current analyses employ period prevalence of MDD referring to the time interval between T25-T30 as the major predictor of interest. The clinical interviewers were blind to subjects' psychiatric history and group membership.

Personal Importance of Religiosity/Spirituality $(\boldsymbol{R} / \mathrm{S})$. R/S was assessed with a single item from the SADS-L. "How important to you is religion or spirituality?" with response options ranging from 1 (not important at all) to 4 (highly important). While comprising one question, these terms constitute the two terms commonly linked in that literature. This item correlates at 0.70 with the Fetzer Institute's well-established, widely deployed full-scale measure of religion and spirituality (Idler et al., 2003, Larson and Larson, 2003, Desrosiers and Miller, 2007). Its construct validity is supported, for example, by our publications confirming the hypothesized modifying effect of religion on depressive illness (Miller et al., 1997, 2012). To maintain consistency with prior practice, the item is dichotomized into highly important/not highly important.

Frequency of attendance at religious/spiritual services. The respondent is asked "how often if at all, do you attend church, synagogue, or other religious or spiritual services?" followed by five response options ranging from "never" to "once a week or more." Again to accord with our prior work (Kasen et al., 2012), attendance at least once a month was classified as frequent.

Recent Negative Life Events. The interview battery included an established checklist of life events that might have affected the respondent in the preceding 6, 12, 18 or 24 months (Holmes and Rahe, 1967). An extensive literature documents that recent negative life events e.g., job loss, death of a child, comprising 43 items on the checklist, are implicated in the onset and recurrence 
of depressive disorders (Kessler, 1997, Kendler et al., 1999). Current research suggests that stressful life events are also linked to altruism and prosocial behaviors (Lim and DeSteno, 2016). Each event has a weight of 1 and summed to produce the total score. Scores range from 0 to 43 . Sociodemographic Factors. The Time 30 interview also inquired about a range of biosocial and religious/spiritual factors, e.g., respondent's age, gender, achieved educational level, religious denomination, service attendance.

Altruism. The 15 item Altruism scale (used here as a synoptic term covering elements of compassion, social love, and human engagement) derives from factor analytic work conducted on a large antecedent multinational survey of religion and spirituality (McClintock et al., 2016). Replication of the factor structure was subsequently undertaken with the data from the current longitudinal investigation (McClintock et al., 2018). Utilizing exploratory structural equation modeling, this study demonstrated that compassion, social love, and human engagement measures loaded onto a common factor, thereby supporting the treatment of the resulting Altruism factor as unidimensional. The factor score was based on the regression method of factor score estimation (Marsh et al., 2010, Schmitt and Sass, 2011). The compassion measure came from work by Krause and Hayward (2015); the social love measure, including empathy and selfsacrifice, derived from Levin, (2000); and human engagement, which includes prosociality, came from Büssing et al., (2005).

The Compassion items are as follows: "When I see someone in a difficult situation I try to imagine how they feel," "I feel compelled to help someone even when doing so requires me to go out of my way," "It's not enough to feel sorry for someone who is in trouble: Whenever it is possible, I must also do something to help them," "I feel sorry for someone who is in trouble 
even when they caused the problem that faces them," "I feel sorry for someone even when they've done something that hurts me."

The four items for Social Love include: "I have always been a devoted friend," "Even strangers deserve our respect," "For a friend in need, I would sacrifice almost anything," "The best kind of love is given freely." Finally, Human Engagement includes prosociality as reflected in these items: "I help others," "I consider the needs of others," "My thoughts are with those in need," "I do good," "I feel connected with others," "I work voluntarily for others." (Note that these rubrics are simply approximations. For example, "My thoughts are with those in need" could as readily be classified as compassion.)

Patient Health Questionnaire (PHQ-9). This is a 9-item instrument for assessing the presence and severity of depressive symptoms in the two weeks preceding the interview administered at T35. These nine items comprise only a dimensional measure of DSM-IV depressive symptoms; it does not generate a clinical diagnosis of depression. The PHQ-9 is a widely used instrument with well-established reliability and construct validity (Kroenke et al., 2001).

\subsection{Statistical Analysis}

MDD at T30 are the predictors of interest for Altruism at T35. Hence, the analytic sample is confined to persons interviewed at both time points $n=230$. (Twenty-six individuals, not present at T30, were assessed at T35 and are excluded from current analyses.) First, we present univariate descriptive statistics pertaining to basic sociodemographic, design, clinical and R/S characteristics of the High Risk and Low Risk groups (Table 1) separately and combined, followed (Table 2) by the rate of altruism for the variables in Table 1.

Screening for confounders proceeds as follows (Hosmer et al., 2013): at the outset all covariates associated with Altruism at $\mathrm{p}<.25$ in these bivariate analyses are entered into the multivariate 
logistic regression model (See Table 1). Thereafter, variables not contributing to the model at $\mathrm{p}<.05$ are deleted. If any regression coefficients of variables retained in the model are altered in magnitude by $>20 \%$ as a result of the deletion, the deleted variable is restored. These iterations continue until all study design variables, statistically important variables, variables required for construction of interaction terms or judged essential for model acceptance, are retained. Finally, variables removed from consideration at the outset of this process are re-assessed by entering them individually into the multivariate model and then repeating the procedures described above. The preceding operations identified the following covariates as requiring control in the multivariate analyses: risk group and generation (the two study design variables), age, gender, education, number of depressive symptoms at Year 35, number of negative life events in the six months prior to the Year 30 interview.

Some members of G1 and G2 contributed more than one child to the study sample. Logistic regression analysis undertaken within the framework of Generalized Estimating Equations (GEE) was conducted to handle clustered data within families based on a quasi-likelihood approach (Liang and Zeger, 1986, Zeger and Liang, 1986). Robust variance estimates were used to approximate the standard errors of the test statistics. Our methods for adjusting for familial clusters was based on extended families involving many relative types among family members. As suggested by Suktitipat et al. (2012), we used an independent correlation matrix and a robust variance estimator when applying GEE to these extended families (Suktitipat et al., 2012). All analyses were conducted using Proc GENMOD in SAS 9.4.

Using maximum likelihood logistic regression, we compute observed odds ratios (OR) and adjusted odds ratios (AOR) for the association of MDD and R/S with Altruism (Table 3). In exploratory analyses, we use first-order interaction terms to identify consequential modification 
of the association of MDD and R/S on altruism. This analysis begins with the a priori hypothesis that $\mathrm{R} / \mathrm{S}$ is positively and MDD negatively associated with altruism, reflecting the predominant findings in previous studies. Statistical significance is set at $\mathrm{p}<.05$ two-tailed throughout.

\subsection{IRB Approval}

The institutional review boards at Yale University, Columbia University and New York State Psychiatric Institute approved all waves of the study. After providing participants with a complete study description, written informed consent was obtained from adults; assent was obtained from minors, accompanied by written consent from parents.

\section{Results}

In the sample overall, the mean age was 42 years. Generations 1, 2 and 3 comprised 15\%, 50\% and $35 \%$ of the sample, respectively. Females constituted about $60 \%$ of the overall sample; $15 \%$ of subjects had a high school degree or less; about $25 \%$ had graduate degrees. The High Risk group constituted roughly $60 \%$ of the total sample. Twenty-one percent of the total sample met criteria for MDD; $31 \%$ for High R/S and 25\% for Altruism (Table 1).

In both the High Risk and Low Risk groups, the rate of altruism was significantly and substantially higher among females as compared with males (Table 2). In the High Risk group only, rates of altruism varied significantly and directly by education, (thereby serving as grounds for controlling for education in the multivariate model). Altruism was higher among persons for whom religion was of central importance in their lives. In the High Risk group, altruism was higher among persons with a history of MDD.

In adjusted analyses in the overall sample, both R/S and MDD were significantly positively associated with altruism, AOR $2.52(95 \%$ CI 1.15 -5.49) p<.02 and AOR 2.43 (95\% CI, $1.05-$ 5.64) $\mathrm{p}<.04$, respectively. In the High Risk group alone, R/S and MDD were each substantially 
and significantly positively associated with altruism, AOR 4.69 (95\% CI 1.39-15.84) and AOL 4.74 (95\% CI 1.92-11.72). However, none of the first order interaction terms comparing parameter estimates for R/S with altruism in the High versus Low Risk groups or for MDD with altruism in the High versus Low Risk groups, met the standard for statistical significance (Table 3). Frequent service attendance was not associated with altruism in either risk group (not displayed).

In the High Risk group, the association of MDD with altruism was strongly affected by the religiosity/spirituality of the individual. Among individuals for whom R/S was not central to their lives, the AOR for the association of MDD with altruism was 3.12 (95\% C.I. 0.64- 15.30). Among persons for whom R/S was of great importance, the association of MDD with altruism was 22.55 (95\%CI 1.23-414.60). Null findings emerged for all comparable analyses in the Low Risk group. Whereas altruism varied strongly gender, gender exerted only this main effect in the multivariate model.

\section{Discussion}

Contrary to our initial hypothesis grounded in antecedent research, we found a significant, moderately strong and direct association of MDD with subsequent altruism. In the sample overall, individuals diagnosed with MDD at T30 were at 2.43 times the odds of being classified as altruistic at T35 compared with that for persons free of this diagnosis at T30 (p<.04). This significant overall adjusted odds ratio of 2.4, absent a significant interaction term, clarifies that the effect of depression on altruism is not confined to the High Risk group but characterizes the overall study sample, albeit with a more modest but still significant effect.

Differences in design, sampling, measurement of depression and timing of assessments between the current and prior work are considerable and may account for some of the discrepancies in 
findings. Two are of special note. First, in most earlier studies, classification of subjects as depressed was based on a cut-point on a symptom checklist (Baron-Cohen et al., 2001, Harkness et al., 2010, Bora and Berk, 2016), rather than on a clinical diagnosis. Such checklists only screen for cases of clinical depression; they do not identify them. Furthermore, the checklists commonly used, e.g., the CES-D (Okun et al., 1996) do not map adequately onto DSM-IV or DSM-V symptom criteria for MDD. As a result, the proportion of true cases among persons screening positive is uncertain. Hence, if the research question concerns the association of major depression and altruism, that question is not addressed in most earlier investigations. Second, the current investigation examines the association of depression and altruism prospectively with MDD measured years prior to that of altruism. Hence, this design adds some clarity to questions of time order but also accommodates to situations in which altruism does not arise immediately in the wake of depression but may require considerable time to emerge.

Despite the greater confidence in time order afforded by prospective designs, the positive association of depression with altruism might be in part an artifact of biased self-reporting. Survey respondents may overstate their altruism to present themselves in a more socially desirable light to the interviewer. However, why this type of misrepresentation would occur disproportionately among persons previously classified as having MDD at T30 has no ready explanation. Moreover, the level of over-reporting would have to be exceedingly high to produce an adjusted odds ratio of 4.76 in the High Risk group.

To evaluate this methodological challenge further, we examined whether commendable sentiments or behaviors other altruism measured at Year 35 were associated with MDD. Several factors, other than altruism, developed by McClintock and colleagues (McClintock et al., 2016) assessed feelings or actions that we would expect respondents to value positively and hence 
endorse if endorsement were driven by considerations of social desirability. The factor "Interconnectedness" comprises items that address ways in which a person experiences a connection to other people, e.g., "all of us share a common bond," "although other people may be difficult, I feel an emotional bond with all humanity." Yet "Interconnectedness" is not associated with MDD either in the overall sample, in the High Risk group, or as a continuous or binary variable, in observed or adjusted analyses. Nor are Forgiveness, Gratitude, Universality, Psychological Love or Social Love. That the association of altruism with MDD is an artifact of social pressures operating differentially as a function of the respondent's psychiatric history is not supported by the evidence internal to this study.

Our finding of a direct effect of MDD on positive internal changes is supported by the abundant literature on posttraumatic growth (PTG). In the past quarter-century, several groups of investigators have identified a beneficial yield from the psychological suffering (as well as physical deprivation) associated with adversity. Staub and Vollhardt advanced the idea that adversity can stimulate selfless acts of kindness, so-called "altruism born of suffering" (Staub and Vollhardt, 2008; Vollhardt and Bilewicz, 2013). Tedeschi and his co-investigators, the first to frame the concept of PTG, approach this issue from a more cognitive and philosophical perspective. In their view, trauma and loss may well take the form of a healthy and productive response involving a subjective sense of having gained a more positive world view, increased personal strength, the acquisition of a more universal, humane perspective on life and spiritual growth (Tedeschi, 1999, 2007). However, whether a person's subjective impressions of change are reflected in altered views about prosocial behavior or expressed in actual observable behavioral gains in altruism, patience, purpose and empathy is in dispute (Frazier et al., 2012). 
To date, few investigations of the possible role of depression as a mechanism for the changes in perspective associated with PTG have appeared (Eisma et al., 2019, Magruder et al., 2015). Negative life events increase the risk of depressive disorder (Dohrenwend, 1998). We considered it possible therefore, that such events would be positively associated with subsequent MDD and thereafter compromise altruism. No such association emerged between life events and MDD emerged. This null finding is not altogether surprising since, in the absence of specific dating of the MDD episodes within the Year25-Year30 interval, we do not know whether they were preceded or followed by the negative events in question.

$\mathrm{R} / \mathrm{S}$ at T30 is positively and significantly associated with altruism at T35 in the High Risk group. This result conforms to our research hypothesis and to common sense expectation given that altruism is valorized by most religions. However, recent challenges to the view of religion as sponsoring altruism indicates that these findings were by no means assured. In recent years a number of articles, primarily methodological, have challenged cross-sectional surveys that claim to document a positive association of R/S with altruism or empathy (Saroglou et al., 2005, Galen and Kloet, 2011, Sablosky, 2014). The critique rests in part on the investigators' reliance on concurrent self-reports of religiosity and altruism in cross-sectional research, a problem from which the current study is exempt.

Studies with substantive findings of an inverse association between religiosity and empathy or altruism have also appeared in recent years (Saslow et al., 2013). Decety and colleagues found lower levels of self-reported altruistic behaviors among children raised in religious households as compared with those in non-religious homes. Further, individual religiosity was inversely associated with children's altruism proper and directly linked to punitive attitudes (Silton and 
Fogel, 2010). Against this backdrop, the current findings offer further support from a longitudinal study naïve to this debate for a positive association between $\mathrm{R} / \mathrm{S}$ and altruism. The principal findings for R/S and MDD as predictors of altruism hold for the sample overall. However, when the High and Low Risk groups are analyzed separately, many findings are confined to the High Risk group although the interaction term testing for a difference between the High and Low Risk groups in this regard was not significant. Similar results have emerged in several other studies based on the same data but using different outcomes (Weissman et al., 1997, Kasen et al., 2012). The risk of prepubertal-onset in the High Risk offspring was more than 10-fold that in the Low Risk; recurrence was also more common among the High Risk (Weissman et al., 2016). The principal findings from several other studies based on these data also hold only for the High Risk. Much the same pattern emerges from some studies of R/S and depression (Braam and Koenig, 2019). We emphasize however that the absence of a statistically significant interaction term in testing whether the association of MDD with altruism in the High Risk versus the Low Risk group differ significantly is difficult to interpret given the comparatively small sample sizes involved. Further research in this area is warranted. The association of MDD with altruism appears to be stronger among people who consider R/S highly important in their lives. If true, what pathway or mechanism gives rise to this especially heightened prosocial response to MDD. The R/S literature offers two potential explanatory frameworks: positive religious coping and relational spirituality. Positive religious coping involves an active, deliberate effort to cultivate spiritual, social support and to cognitively reframe adversity based upon religious principles (Pargament, 1997, Pargament and Park, 1995). Numerous studies have established that positive religious coping in the face of stress and negative life events leads to long term mental health and physical health (Pargament et al., 2004). 
To date, this approach has not been extended to work on coping with a clinical diagnosis of MDD. Within this framework, altruism in the face of MDD may represent a form of religious coping by serving people in need, and cognitive reframing of one's own suffering as a catalyst for assisting humanity.

Relational spirituality, a relational style linked to generativity and improved mental health, offers a complimentary explanatory framework (Sandage et al., 2010, 2011). Relational spirituality is a way of relating to the sacred, including ourselves and other people, that allows for imperfection and still seeks greater goodness. From this perspective, altruism is an embrace of the brokenness in ourselves and other people, coupled with hope for human betterment. From within both frameworks, R/S offers a strategy to meaningfully engage people in the face of depression; providing hope, connection and support to counter the felt isolation and social disengagement of MDD.

\section{Limitations}

Several features of this investigation restrict our confidence in reported findings. Potentially important information is lacking for the period between T30 and T35. Therefore the possibility exists that other unmeasured factors or psychiatric disturbances occurring in this interval might better explain the positive association of MDD at T30 with altruism at T35.

The measure of altruism is based on self-report, thereby creating the opportunity for biased reporting based on exposure status. As noted earlier, self-report bias is not likely to explain the positive association of altruism with depression entirely. However, it remains true that we do not know the degree to which verbal representations of altruistic feelings and actions correspond to the feelings and actions themselves if they correspond at all. A caveat that applies as well to much of the literature on posttraumatic growth. We note, in this regard, that the interview 
protocol did not obtain information on personality traits, thereby precluding an investigation of their contribution to the reported associations.

The current sample had only limited statistical power to test, for example, whether the results reported for the sample combining religious and spiritual subjects held separately for the religious, not spiritual group and for the spiritual, not religious group. Further examination of this issue is clearly warranted.

Identification of the spiritual and religious practices that may increase a person's altruism or likelihood of developing MDD is an extremely important question and one that can only be addressed in a longitudinal study. Regrettably, the current study was not developed with these types of questions in mind. Hence, we do not have adequately detailed information on spiritual or religious practices to examine the mechanisms by which $\mathrm{R} / \mathrm{S}$ fosters altruism or reduces the risk of MDD.

In observational studies, residual confounding that inflates or deflates the magnitude of the measure of association, cannot be directly estimated or addressed, introducing some uncertainty as to the magnitude and even direction of the measure of effect. Finally, we emphasize that the design used to examine the relationship of study measures in the period between Year30 and Year35 does not constitute a cross-lagged panel design. MDD is measured only at Year30; altruism, only at Year35. As a consequence, major strengths of classic cross-lagged designs, i.e., assessment of reciprocal relationships or of the direction of certain observed associations, both matters of growing interest (Braam and Koenig, 2019), are not available.

\section{Conclusions}

Whereas MDD is a principal "risk factor" in the context of the current investigation, the outcome is not pathology or impairment, but altruism, a prized attribute. The value of suffering, whether 
associated with clinical depression or social adversity, as fuel for psychotherapeutic work and positive change is well established. Mention should also be made here of the key role that suffering and depression can play in spiritually-oriented psychotherapies as it can in pastoral work insofar as these misfortunes create opportunities for spiritual growth and healing. 


\section{References}

Ambrosini, P.J., 2000. Historical development and present status of the Schedule for Affective Disorders and Schizophrenia for School-Age Children (K-SADS). J. Am. Acad. Child Adolesc. Psychiatry. 39, 49-58. https://doi.org/10.1097/00004583-200001000-00016

Baron-Cohen, S., Wheelwright, S., Hill, J., Raste, Y., Plumb, I., 2001. The "Reading the Mind in the Eyes" Test revised version: a study with normal adults, and adults with Asperger syndrome or high-functioning autism. J. Child Psychol. Psychiatry. 42, 241-251. https://doi.org/10.1111/1469-7610.00715

Bora, E., Berk, M., 2016. Theory of mind in major depressive disorder: a meta-analysis. J. Affect. Disord. 191, 49-55. https://doi.org/10.1016/j.jad.2015.11.023

Braam, A.W., Koenig, H.G., 2019. Religion, spirituality and depression in prospective studies: A systematic review. J. Affect. Disord. 257, 428-438. https://doi.org/10.1016/j.jad.2019.06.063

Büssing, A., Ostermann, T., Matthiessen, P.F., 2005. Role of religion and spirituality in medical patients: confirmatory results with the SpREUK questionnaire. Heal. Qual. Life Outcomes. 3, 10. https://doi.org/10.1186/1477-7525-3-10

Clark, C.B., Thorne, C.B., Hardy, S., Cropsey, K.L., 2013. Cooperation and depressive symptoms. J. Affect. Disord. 150, 1184-1187. https://doi.org/10.1016/j.jad.2013.05.011

Cusi, A.M., MacQueen, G.M., Spreng, R.N., McKinnon, M.C., 2011. Altered empathic responding in major depressive disorder: relation to symptom severity, illness burden, and psychosocial outcome. Psychiatry Res. 188, 231-236. https://doi.org/10.1016/j.psychres.2011.04.013

Decety, J., 2010. The neurodevelopment of empathy in humans. Dev. Neurosci. 32, 257-267. 
https://doi.org/10.1159/000317771

Desrosiers, A., Miller, L., 2007. Relational spirituality and depression in adolescent girls. J. Clin. Psychol. 63, 1021-1037. https://doi.org/10.1002/jclp.20409

Dohrenwend, B.P., 1998. Adversity, stress, and psychopathology, in: Adversity, Stress, and Psychopathology.

Donges, U.S., Kersting, A., Dannlowski, U., Lalee-Mentzel, J., Arolt, V., Suslow, T., 2005. Reduced awareness of others' emotions in unipolar depressed patients. J. Nerv. Ment. Dis. 193, 331-337. https://doi.org/10.1097/01.nmd.0000161683.02482.19

Eisenberg, N., Miller, P.A., 1987. The relation of empathy to prosocial and related behaviors. Psychol. Bull. 101, 91-119. https://doi.org/10.1037/0033-2909.101.1.91

Eisma, M.C., Lenferink, L.I.M., Stroebe, M.S., Boelen, P.A., Schut, H.A.W., 2019. No pain, no gain: cross-lagged analyses of posttraumatic growth and anxiety, depression, posttraumatic stress and prolonged grief symptoms after loss. Anxiety, Stress Coping 32, 231-243. https://doi.org/10.1080/10615806.2019.1584293

Ekinci, O., Ekinci, A., 2016. Relationship between empathic responding and its clinical characteristics in patients with major depressive disorder. Dusunen Adam J. Psychiatry Neurol. Sci. 29, 145-154. https://doi.org/10.5350/dajpn2016290206

Fendrich, M., Warner, V., Weissman, M.M., 1990. Family Risk Factors, Parental Depression, and Psychopathology in Offspring. Dev. Psychol. 26, 40-50. https://doi.org/10.1037/00121649.26.1.40

Frazier, P., Greer, C., Gabrielsen, S., Tennen, H., Park, C., Tomich, P., 2012. The relation between trauma exposure and prosocial behavior. Psychol. Trauma Theory, Res. Pract. Policy. 5, 286-294. https://doi.org/10.1037/a0027255 
Galen, L.W., Kloet, J.D., 2011. Mental well-being in the religious and the non-religious:

evidence for a curvilinear relationship. Ment. Heal. Relig. Cult. 14, 673-689. https://doi.org/10.1080/13674676.2010.510829

Greenberg, D.M., Baron-Cohen, S., Rosenberg, N., Fonagy, P., Rentfrow, P.J., 2018. Elevated empathy in adults following childhood trauma. PLoS One 13. https://doi.org/10.1371/journal.pone.0203886

Harkness, K.L., Jacobson, J.A., Duong, D., Sabbagh, M.A., 2010. Mental state decoding in past major depression: Effect of sad versus happy mood induction. Cogn. Emot. 24, 497-513. https://doi.org/10.1080/02699930902750249

Harkness, K.L., Sabbagh, M.A., Jacobson, J.A., Chowdrey, N.K., Chen, T., 2005. Enhanced accuracy of mental state decoding in dysphoric college students. Cogn. Emot. https://doi.org/10.1080/02699930541000110

Holmes, T.H., Rahe, R.H., 1967. The social readjustment rating scale. J. Psychosom. Res. 11, 213-221. https://doi.org/10.1016/0022-3999(67)90010-4

Hosmer, D.W., Lemeshow, S., Sturdivant, R.X., 2013. Applied Logistic Regression: Third Edition, Applied Logistic Regression: Third Edition. https://doi.org/10.1002/9781118548387

Idler, E.L., Musick, M.A., Ellison, C.G., George, L.K., Krause, N., Ory, M.G., Pargament, K.I., Powell, L.H., Underwood, L.G., Williams, D.R., 2003. Measuring multiple dimensions of religion and spirituality for health research: Conceptual background and findings from the 1998 general social survey. Res. Aging 25, 327-365. https://doi.org/10.1177/0164027503025004001

Kasen, S., Wickramaratne, P., Gameroff, M.J., Weissman, M.M., 2012. Religiosity and 
resilience in persons at high risk for major depression. Psychol. Med. 42, 509-519. https://doi.org/10.1017/S0033291711001516

Kendler, K.S., Karkowski, L.M., Prescott, C.A., 1999. Causal relationship between stressful life events and the onset of major depression. Am. J. Psychiatry. 156, 837-841. https://doi.org/10.1176/ajp.156.6.837

Kessler, R.C., 1997. The effects of stressful life events on depression. Annu. Rev. Psychol. 48, 191-208. https://doi.org/10.1146/annurev.psych.48.1.191

Krause, N., Hayward, R.D., 2015. Humility, compassion, and gratitude to God: assessing the relationships among key religious virtues. Psycholog. Relig. Spiritual. 7, 192-204. https://doi.org/10.1037/rel0000028

Kroenke, K., Spitzer, R.L., Williams, J.B.W., 2001. The PHQ-9: validity of a brief depression severity measure. J. Gen. Intern. Med. 16, 606-613. https://doi.org/10.1046/j.15251497.2001.016009606.x

Kupferberg, A., Bicks, L., Hasler, G., 2016. Social functioning in major depressive disorder. Neurosci. Biobehav. Rev. https://doi.org/10.1016/j.neubiorev.2016.07.002

Larson, D.B., Larson, S.S., 2003. Spirituality's potential relevance to physical and emotional health: a brief review of quantitative research. J. Psychol. Theol. 31, 37-51. https://doi.org/10.1177/009164710303100104

Levin, J., 2000. A prolegomenon to an epidemiology of love: theory, measurement, and health outcomes. J. Soc. Clin. Psychol. 19, 117-136. https://doi.org/10.1521/jscp.2000.19.1.117

Liang, K.Y., Zeger, S.L., 1986. Longitudinal data analysis using generalized linear models. Biometrika. 73, 13-22. https://doi.org/10.1093/biomet/73.1.13

Lim, D., DeSteno, D., 2016. Suffering and compassion: the links among adverse life 
experiences, empathy, compassion, and prosocial behavior. Emotion. 16, 175-182. https://doi.org/10.1037/emo0000144

Magruder, K.M., Kiliç, C., Koryürek, M.M., 2015. Relationship of posttraumatic growth to symptoms of posttraumatic stress disorder and depression: A pilot study of Iraqi students. Int. J. Psychol. 50, 402-406. https://doi.org/10.1002/ijop.12146

Mannuzza, S., Fyer, A.J., Klein, D.F., Endicott, J., 1986. Schedule for Affective Disorders and Schizophrenia-Lifetime version modified for the study of anxiety disorders (SADS-LA): rationale and conceptual development. J. Psychiatr. Res. 20, 317-325. https://doi.org/10.1016/0022-3956(86)90034-8

Marsh, H.W., Lüdtke, O., Muthén, B., Asparouhov, T., Morin, A.J.S., Trautwein, U., Nagengast, B., 2010. A new look at the Big Five Factor Structure through Exploratory Structural Equation Modeling. Psychol. Assess. 22, 471-491. https://doi.org/10.1037/a0019227

McClintock, C.H., Anderson, M., Svob, C., Wickramaratne, P., Neugebauer, R., Miller, L., Weissman, M.M., 2018. Multidimensional understanding of religiosity/spirituality: relationship to major depression and familial risk. Psychol. Med. 1-10. https://doi.org/10.1017/S0033291718003276

McClintock, C.H., Lau, E., Miller, L., 2016. Phenotypic dimensions of spirituality: Implications for mental health in China, India, and the United States. Front. Psychol. 7. https://doi.org/10.3389/fpsyg.2016.01600

Miller, L., Warner, V., Wickramaratne, P., Weissman, M., 1997. Religiosity and depression: tenyear follow-up of depressed mothers and offspring. J. Am. Acad. Child Adolesc. Psychiatry. 36, 1416-1425. https://doi.org/10.1097/00004583-199710000-00024

Miller, L., Wickramaratne, P., Gameroff, M.J., Sage, M., Tenke, C.E., Weissman, M.M., 2012. 
Religiosity and major depression in adults at high risk: a ten-year prospective study. Am. J. Psychiatry. 169, 89-94. https://doi.org/10.1176/appi.ajp.2011.10121823

Nejati, V., Zabihzadeh, A., Maleki, G., Tehranchi, A., 2012. Mind reading and mindfulness deficits in patients with major depression disorder. Procedia - Soc. Behav. Sci. 32, 431-437. https://doi.org/10.1016/j.sbspro.2012.01.065

Okun, A., Stein, R.E.K., Bauman, L.J., Silver, E.J., 1996. Content validity of the Psychiatric Symptom Index, CES-Depression Scale, and State-Trait Anxiety Inventory from the Perspective of DSM-IV. Psychol. Rep. 79, 1059-1069. https://doi.org/10.2466/pr0.1996.79.3.1059

Pargament, K.I., 1997. The Psychology of Religion and Coping: Theory Research Practice. Guilford Press, New York, NY, US.

Pargament, K.I., Koenig, H.G., Tarakeshwar, N., Hahn, J., 2004. Religious coping methods as predictors of psychological, physical and spiritual outcomes among medically ill elderly patients: A two-year longitudinal study. J. Health Psychol. 9, 713-730. https://doi.org/10.1177/1359105304045366

Pargament, K.I., Park, C.L., 1995. Merely a defense? The variety of religious means and ends. J. Soc. Issues 51, 13-32. https://doi.org/10.1111/j.1540-4560.1995.tb01321.x

Regier, D.A., Burke, J.D., 1987. Psychiatric disorders in the community: the Epidemiological Catchment Area Study. Am. Psychiatr. Assoc. Annu. Rev. 6, 610-624.

Sablosky, R., 2014. Does religion foster generosity? Soc. Sci. J. 51, 545-555. https://doi.org/10.1016/j.soscij.2014.03.012

Sandage, S.J., Hill, P.C., Vaubel, D.C., 2011. Generativity, relational spirituality, gratitude, and mental health: Relationships and pathways. Int. J. Psychol. Relig. 21, 1-16. 
https://doi.org/10.1080/10508619.2011.532439

Sandage, S.J., Jankowski, P.J., Link, D.C., 2010. Quest and Spiritual Development Moderated by Spiritual Transformation. J. Psychol. Theol. 38, 15-31. https://doi.org/10.1177/009164711003800102

Saroglou, V., Pichon, I., Trompette, L., Verschueren, M., Dernelle, R., 2005. Prosocial behavior and religion: new evidence based on projective measures and peer ratings. J. Sci. Study Relig. 44, 323-348. https://doi.org/10.1111/j.1468-5906.2005.00289.x

Saslow, L.R., Willer, R., Feinberg, M., Piff, P.K., Clark, K., Keltner, D., Saturn, S.R., 2013. My brother's keeper?: compassion predicts generosity more among less religious individuals. Soc. Psychol. Personal. Sci. 4, 31-38. https://doi.org/10.1177/1948550612444137

Schmitt, T.A., Sass, D.A., 2011. Rotation criteria and hypothesis testing for exploratory factor analysis: implications for factor pattern loadings and interfactor correlations. Educ. Psychol. Meas. 71, 95-113. https://doi.org/10.1177/0013164410387348

Silton, N.R., Fogel, J., 2010. Religiosity, empathy, and psychopathology among young adult children of rabbis. Arch. Psychol. Relig. 32, 277-291. https://doi.org/10.1163/157361210X532040

Staub, E., Vollhardt, J., 2008. Altruism born of suffering: the roots of caring and helping after victimization and other trauma. Am. J. Orthopsychiatry. 78, 267-280. https://doi.org/10.1037/a0014223

Suktitipat, B., Mathias, R.A., Vaidya, D., Yanek, L.R., Young, J.H., Becker, L.C., Becker, D.M., Wilson, A.F., Daniele Fallin, M., 2012. The robustness of generalized estimating equations for association tests in extended family data. Hum. Hered. 74, 17-26. https://doi.org/10.1159/000341636 
Tedeschi, R.G., 1999. Violence transformed: posttraumatic growth in survivors and their societies. Aggress. Violent Behav. 4, 319-341. https://doi.org/10.1016/s13591789(98)00005-6

Tedeschi, R.G., Calhoun, L.G., Cann, A., 2007. Evaluating resource gain: understanding and misunderstanding posttraumatic growth. Appl. Psychol. 56, 396-406. https://doi.org/10.1111/j.1464-0597.2007.00299.x

Tone, E.B., Tully, E.C., 2014. Empathy as a "risky strength": a multilevel examination of empathy and risk for internalizing disorders. Dev. Psychopathol. 26, 1547-1565. https://doi.org/10.1017/s0954579414001199

Weissman, M.M., Warner, V., Wickramaratne, P., Moreau, D., Olfson, M. V, 1997. Offspring of depressed parents: 10 years later. Arch. Gen. Psychiatry. 54, 932-940. https://doi.org/10.1001/archpsyc.1997.01830220054009

Weissman, M.M., Wickramaratne, P., Gameroff, M.J., Warner, V., Pilowsky, D., Kohad, R.G., Verdeli, H., Skipper, J., Talati, A., 2016. Offspring of depressed parents: 30 years later. Am. J. Psychiatry. 173, 1024-1032. https://doi.org/10.1176/appi.ajp.2016.15101327

Zahn-Waxler, C., Van Hulle, C., 2012. Empathy, guilt, and depression: when caring for others becomes costly to children, in: Oakley, B., Knafo, A., Madhavan, G., Wilson, D. (Eds.), Pathological Altruism. Oxford University Press, Oxford, New York, pp. 321-344. https://doi.org/10.1093/acprof:oso/9780199738571.003.0224

Zeger, S.L., Liang, K.-Y., 1986. Longitudinal Data Analysis for Discrete and Continuous Outcomes. Biometrics 42, 121. https://doi.org/10.2307/2531248 


\begin{tabular}{|c|c|c|c|}
\hline Characteristic & Total & High Risk & Low Risk \\
\hline Age, mean (SD) & $41.64(17.72)$ & $41.60(17.11)$ & $41.73(18.86)$ \\
\hline \multicolumn{4}{|l|}{ Generation, $n(\%)$} \\
\hline Generation 1 & $41(14.6)$ & $26(14.6)$ & $15(14.4)$ \\
\hline Generation 2 & $141(50.0)$ & $91(51.1)$ & $50(48.1)$ \\
\hline Generation 3 & $99(35.4)$ & $60(33.7)$ & $39(37.5)$ \\
\hline \multicolumn{4}{|l|}{ Gender, $n(\%)$} \\
\hline Female & $169(59.9)$ & $113(63.5)$ & $56(53.8)$ \\
\hline Male & $112(39.7)$ & $64(36.0)$ & $48(46.2)$ \\
\hline \multicolumn{4}{|l|}{ Education level, $n(\%)$} \\
\hline Graduate degree & $56(24.0)$ & $33(22.4)$ & $23(26.7)$ \\
\hline Bachelor's degree & $56(24.0)$ & $33(22.4)$ & $23(26.7)$ \\
\hline $\begin{array}{l}\text { Associate's degree or } \\
\text { some college }\end{array}$ & $86(36.9)$ & $59(40.1)$ & $27(31.4)$ \\
\hline $\begin{array}{l}\text { High school degree or } \\
\text { some high school }\end{array}$ & $35(15.0)$ & $22(15.0)$ & $13(15.1)$ \\
\hline \multicolumn{4}{|l|}{ Religious Affiliation, $\boldsymbol{n}(\%) * * *$} \\
\hline Protestant & $43(17.1)$ & $32(19.6)$ & $11(12.5)$ \\
\hline Roman Catholic & $128(51.0)$ & $67(41.1)$ & $61(69.3)$ \\
\hline Other religious affiliation $^{\mathrm{b}}$ & $31(12.4)$ & $27(16.6)$ & $4(4.5)$ \\
\hline Agnostic/other & $49(19.5)$ & $37(22.7)$ & $12(13.6)$ \\
\hline Frequent Attendance, $\boldsymbol{n}(\%) * * *$ & $95(37.7)$ & $50(31.1)$ & $45(49.5)$ \\
\hline Negative Life Events Past 6 & $1.77(2.93)$ & $1.97(3.45)$ & $1.41(1.62)$ \\
\hline \multicolumn{4}{|l|}{ Months, mean (SD) } \\
\hline \multicolumn{4}{|l|}{ Risk Groups, $n$ (\%) } \\
\hline High-Risk & $138(64.2)$ & $138(100)$ & - \\
\hline Low-Risk & $77(35.8)$ & - & $77(100)$ \\
\hline \multicolumn{4}{|l|}{ MDD, $n(\%) * * *$} \\
\hline Present & $58(21.7)$ & $47(27.6)$ & $11(11.3)$ \\
\hline Absent & $157(76.6)$ & $96(72.2)$ & $61(84.7)$ \\
\hline \multicolumn{4}{|l|}{ High R/S, $n(\%)$} \\
\hline Present & $81(30.7)$ & $51(30.7)$ & $30(30.6)$ \\
\hline Absent & $147(72.4)$ & $94(72.3)$ & $53(72.6)$ \\
\hline \multicolumn{4}{|l|}{ Altruism, $n(\%)$} \\
\hline Present & $70(24.8)$ & $45(25.3)$ & $25(24.0)$ \\
\hline Absent & $163(75.8)$ & $104(75.4)$ & $59(76.6)$ \\
\hline
\end{tabular}

${ }^{a}$ Generation 4 and "married-ins" in Generations 2 and 3 are excluded from the analytic sample.

${ }^{\mathrm{b}}$ Jewish, Buddhist, Hindu, Eastern Orthodox. 
Table 2. Rates of Altruism by Major Sociodemographic, Design, Clinical and Religiosity/Spirituality Characteristics by Risk Group ${ }^{a}$

\begin{tabular}{|c|c|c|}
\hline \multirow[b]{3}{*}{ Characteristic } & \multicolumn{2}{|c|}{ Risk Group } \\
\hline & High & Low \\
\hline & $\%$ & $\%$ \\
\hline \multicolumn{3}{|l|}{ Age in years } \\
\hline $13-24$ & 29.0 & 24.0 \\
\hline $25-40$ & 20.0 & 28.6 \\
\hline $41-53$ & 21.1 & 18.2 \\
\hline $54-83$ & 29.3 & 21.1 \\
\hline \multicolumn{3}{|l|}{ Generation } \\
\hline Generation 1 & 26.9 & 20.0 \\
\hline Generation 2 & 24.4 & 23.7 \\
\hline Generation 3 & 25.0 & 23.1 \\
\hline \multicolumn{3}{|l|}{ Gender } \\
\hline Female & $30.8 *$ & $34.7 * *$ \\
\hline Male & 15.0 & 9.3 \\
\hline \multicolumn{3}{|l|}{ Education level } \\
\hline Graduate degree & 40.0 & 13.6 \\
\hline Bachelor's degree & 31.3 & 22.7 \\
\hline $\begin{array}{l}\text { Associate's degree or } \\
\text { some college }\end{array}$ & 11.1 & 19.0 \\
\hline $\begin{array}{l}\text { High school degree or } \\
\text { some high school }\end{array}$ & $15.8 *$ & 50.0 \\
\hline \multicolumn{3}{|l|}{ Religious Affiliation $* * *$} \\
\hline Roman Catholic & 22.6 & 17.0 \\
\hline Protestant, other & 23.3 & 44.4 \\
\hline Other Religious Affiliation ${ }^{b}$ & 22.7 & 50.0 \\
\hline Agnostic & 30.6 & 27.3 \\
\hline \multicolumn{3}{|l|}{ Risk Group } \\
\hline High-Risk & 25.0 & - \\
\hline Low-Risk & - & 22.8 \\
\hline \multicolumn{3}{|l|}{$\mathbf{R} / \mathbf{S}$} \\
\hline Present & $37.5 *$ & 29.6 \\
\hline Absent & 20.0 & 20.3 \\
\hline \multicolumn{3}{|l|}{ Frequent Attendance } \\
\hline Yes & 31.3 & 25.0 \\
\hline
\end{tabular}


No

MDD, $\boldsymbol{n}(\%)$

Present

Absent
22.0

$39.5 *$

20.2
20.0

18.2

23.0

a G4 and "married-ins" are excluded from the analytic sample.

b Jewish, Buddhist, Hindu, Eastern Orthodox.

$* \mathrm{p}<.05$
$* * \mathrm{p}<.01$
$* * * \mathrm{p}<.005$




\begin{tabular}{|c|c|c|c|c|c|c|}
\hline \multirow{2}{*}{$\begin{array}{l}\text { Risk Group and } \\
\text { Religiosity/Spirituality } \\
\text { Variables }\end{array}$} & \multicolumn{3}{|c|}{ Univariate Models } & \multicolumn{3}{|c|}{ Multivariate Models b } \\
\hline & $\begin{array}{l}\text { Odds } \\
\text { Ratio }\end{array}$ & $95 \% \mathrm{CI}$ & $\mathbf{p}$ & $\begin{array}{l}\text { Odds } \\
\text { Ratio }\end{array}$ & $95 \% \mathrm{CI}$ & $\mathbf{p}$ \\
\hline \multicolumn{7}{|l|}{ Combined Samples } \\
\hline $\begin{array}{l}\text { Religiosity/Spirituality } \\
\text { Major Depressive } \\
\text { Disorder }\end{array}$ & 2.24 & $1.20-4.18$ & 0.01 & 2.43 & $1.05-5.64$ & 0.02 \\
\hline \multicolumn{7}{|l|}{ High-Risk Group } \\
\hline $\begin{array}{l}\text { Religiosity/Spirituality } \\
\text { highly important }\end{array}$ & 2.40 & $1.13-5.11$ & 0.03 & 4.69 & $1.39-15.84$ & 0.013 \\
\hline $\begin{array}{l}\text { Major Depressive } \\
\text { Disorder }\end{array}$ & 2.59 & $1.21-5.55$ & 0.02 & 4.74 & $1.92-11.72$ & 0.001 \\
\hline \multicolumn{7}{|l|}{ Low-Risk Group } \\
\hline $\begin{array}{l}\text { Religiosity/Spirituality } \\
\text { highly important }\end{array}$ & 1.6 & $0.58-4.67$ & 0.45 & 1.55 & $0.38-6.29$ & 0.54 \\
\hline $\begin{array}{l}\text { Major Depressive } \\
\text { Disorder }\end{array}$ & 0.74 & $0.15-3.78$ & 0.73 & 0.89 & $0.06-13.88$ & 0.93 \\
\hline \multicolumn{7}{|c|}{$\begin{array}{l}\text { a High or low risk is based on the depression status of the founding members of each group: lifetime } \\
\text { history of major depression; absence at time of interview of a history of any major psychiatric disorder, } \\
\text { respectively. } \\
\text { b For each of the two multivariate models the primary outcome variable is altruism. The following } \\
\text { variables served as covariates: age, gender, generation, risk group, education, number depressive } \\
\text { symptoms at Year } 35 \text {, number of negative life events in the } 6 \text { months prior to the Year } 30 \text { interview. } \\
\text { Alternative time frames for the report of negative life events, i.e., 12, } 18 \text { or } 24 \text { months, did not } \\
\text { appreciably alter the parameter estimates of interest. }\end{array}$} \\
\hline
\end{tabular}




\section{Author Contributions}

$\mathrm{RN}$ framed the current research question, drafted the manuscript and, together with PW, analyzed the data. CHM, advised by LM, developed the measure of altruism. RN, PW, CS, CHM, MJG, LM and AC contributed to the interpretation and elaboration of study findings. RN, PW, CS and LM collaborated in the writing of the final manuscript. MJG contributed to data preparation.

\section{Acknowledgments}

We are pleased to acknowledge the generosity of Dr. Myrna Weissman for providing access to the data necessary for the analyses reported here. This project was made possible in part through the support of a grant from the John Templeton Foundation. The opinions expressed in this publication are those of the authors and do not necessarily reflect the views of the John Templeton Foundation.

\section{Financial Disclosures}

This study was supported in part by the John Templeton Foundation grant \#54679 (MMW), \#61330 (MMW), and NIMH grant 2-R01-MH36197 (MMW).

\section{Author Disclosures}

The authors have no disclosures to report. The funders had no role in study design, data collection and analysis, decision to publish, or preparation of the manuscript.

\section{Conflict of Interest}

None of the authors have a conflict of interest. 